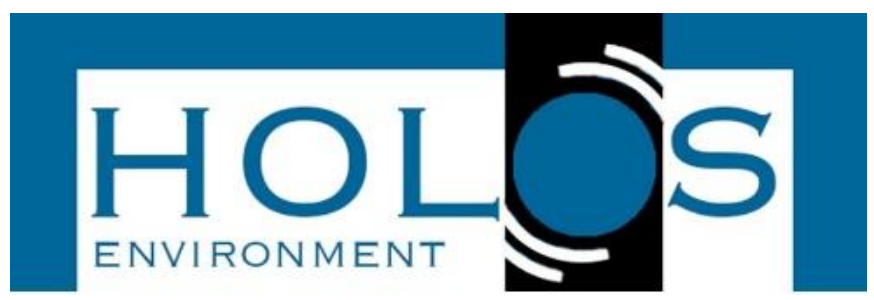

\title{
INDICADORES DE SUSTENTABILIDADE EM DUAS ÁREAS DISTINTAS, EM CALDAS/MG, ATRAVÉS DA METODOLOGIA MESMIS
}

\section{SUSTAINABILITY INDICATORS IN TWO DISTINCT AREAS, IN CALDAS/MG, THROUGH THE MESMIS METHODOLOGY}

\author{
Milta Margaret Barbosa ${ }^{1}$, Jéssica Daiane dos Reis ${ }^{1}$, Otavio Duarte Giunti ${ }^{1}$, Ariana \\ Vieira Silva ${ }^{1}$
}

Artigo recebido em: 14/03/2016 e aceito para publicação em: 28/10/2016.

DOI: http://dx.doi.org/10.14295/holos.v17i1.11204

\begin{abstract}
Resumo: O desenvolvimento sustentável é condição essencial para reverter e minimizar os impactos decorrentes das mudanças oriundas da intervenção humana nos recursos ambientais. Esse trabalho teve por objetivos a criação, seleção e aplicação de indicadores de sustentabilidade, por meio de diagnóstico visual, composto por 26 parâmetros indicadores através da metodologia MESMIS. Foram escolhidas duas áreas para a aplicação, uma constituída por um fragmento de mata nativa e a outra constituída por área de pastagem, próxima a uma nascente, ambas na Fazenda Pedra Branca, município de Caldas, no sul de Minas Gerais, que está inserida dentro da Área de Proteção Ambiental (APA) Santuário Ecológico da Pedra Branca. Como resultados, o fragmento de mata apresentou elevado índice de sustentabilidade, sendo necessário um baixo manejo da área. Já a área de pastagem apresentou vários pontos críticos a serem melhorados. A maior parte dos pontos críticos está relacionada à pouca diversidade ecológica da área e sugere-se como alternativa para elevar a diversidade a integração entre a manejo da pastagem e a produção florestal, através da inserção de ilhas e aleias compostas por espécies arbóreo-arbustivas. Também é proposta a recomposição da vegetação ciliar da nascente próxima à pastagem, em área rural consolidada.
\end{abstract}

Palavras-chave: Desenvolvimento Sustentável. Fragmento Florestal. Pastagem. Área de Proteção Ambiental.

Abstract: Sustainable development is essential to reverse and minimize the impacts of the changes arising from human intervention on environmental resources. This study aimed to the creation, selection and application of sustainability indicators, through visual diagnosis, composed of 26 indicators parameters by MESMIS methodology. Two areas were chosen for the application, consisting of a fragment of native forest and the other consisting of pasture, next to a river source, both at Fazenda Pedra Branca, municipality of Caldas, southern Minas Gerais state, which is inserted into the Environmental Protection Area Ecological Sanctuary of Pedra Branca. As a result, the forest fragment showed high sustainability index, a low management of the area is required. Already the pasture area showed several critical points to be improved. The most critical point is related to the low ecological diversity of the area and it is suggested as an alternative to increase the diversity integration between the management of grazing and forestry production through the inclusion of islands and alley crops composed

IFSULDEMINAS / Campus Muzambinho. Emails: (miltamargaretbarbosa@gmail.com,

12131002330@muz.ifsuldeminas.edu.br, otavio.giunti@muz.ifsuldeminas.edu.br, ariana.silva@muz.ifsul deminas .edu.br)

Holos Environment (2017), 17 (1): 1-14. 1 
of tree and shrub species. It's also proposed the restoration of ciliar vegetation from the river source next pasture, on a consolidated rural area.

Keywords: Sustainable development. Forest fragment. Pasture. Environmental Protection Area.

\section{INTRODUÇÃO}

O desenvolvimento rural sustentável surge como uma condição essencial para reverter a situação atual dos sistemas produtivos, em sua maioria caracterizados por uma simplificação da agricultura, evidenciada pela monocultura, uso intensivo dos solos, utilização em larga escala de insumos químicos sintéticos e manipulação genética de plantas, uma vez que a sustentabilidade indica uma condição de colheita perpétua de biomassa em um sistema que não apresenta sua capacidade de renovação comprometida e é uma condição fundamental para qualquer atividade econômica (GLIESSMAN, 2009; RUIZ et al., 2009).

No processo de concepção do desenvolvimento sustentável é fundamental a compreensão do que é e como deve ser medida a sustentabilidade, uma vez que a evidência da sustentabilidade está sempre no futuro, não sendo visualizada em curto prazo (CARVALHO, 1993; GLIESSMAN, 2009). Para Verona et al. (2007), a determinação da sustentabilidade de um local ou de uma atividade favorece o reconhecimento dos impactos oriundos dessas atividades e a busca por soluções que possam mitigar esses impactos, sendo fundamental, para uma correta e adequada observação dos ecossistemas agrícolas, em suas dimensões socioeconômica e ambiental, a operacionalização do conceito de sustentabilidade.

Assim, para auxiliar a mensuração da sustentabilidade, uma das ferramentas utilizadas é o uso de indicadores, capazes de revelar alterações ambientais e suas consequências, permitindo uma análise dos benefícios oriundos do manejo sobre uma determinada área, contribuindo para a tomada de decisões que visem 0 desenvolvimento sustentável (CÂNDIDO et al., 2015; GUIMARÃES et al. 2015). Moura, Almeida e Miguel (2004) salientam que os indicadores permitem avaliar e comunicar, de modo simplificado, as intervenções e modificações antrópicas ocorridas em um determinado sistema e o estado deste em relação a alguns critérios utilizados para a avaliação de sua sustentabilidade. 
O uso de indicadores, por estabelecer a visão de conjunto do sistema, proporciona o direcionamento de um caminho para a construção de agroecossistemas mais adequados, por indicarem a direção e a prioridade das mudanças e também para a formulação de estratégias políticas, de planejamento e decisões mais acertadas a serem tomadas em direção a um desenvolvimento sustentável (MALHEIROS; PHILIPPI; COUTINHO, 2008; VERONA, 2008).

Uma das ferramentas metodológica utilizada para a avaliação da sustentabilidade em um agroecossistema é o método MESMIS (Marco de Avaliação de Sistemas de Manejo de Recursos Naturais Incorporando Indicadores de Sustentabilidade), que resultou de um trabalho interdisciplinar e multi-institucional, organizado pelo Grupo Interdisciplinar de Tecnologia Rural Apropriada (GIRA), com utilização em projetos florestais, agrícolas e pecuários, validado em áreas distintas das ciências agrárias, com validação em muitas regiões do mundo (ASTIER et al., 2012; DEPONTI; ECKERT: AZAMBUJA, 2002). A abordagem nessa metodologia é sistêmica, interdisciplinar e participativa, buscando entender e atender cada agroecossistema em sua complexidade e especificidade (SPEELMAN et al., 2007).

A metodologia MESMIS é voltada para a agricultura familiar e avalia a sustentabilidade de um agroecossistema a partir de suas três principais dimensões ambiental, econômica e social e suas inter-relações, buscando a redução das diferenças sociais, o gerenciamento adequado dos recursos ambientais, com sua utilização promovendo danos mínimos ao ambiente, objetivando corrigir e minimizar os pontos críticos observados (SANTANA et al., 2015). Assim, essa metodologia, por ser realizada em uma espiral de sucessivas avaliações, permite a construção de um agroecossistema sustentável, através da formulação de estratégias políticas e de planejamento adequadas (KEMERICH et al., 2013; KEMERICH, RITTER, BORBA, 2014).

A metodologia MESMIS baseia-se na apropriação coletiva da realidade local, construção conjunta de indicadores, com a aprovação da comunidade residente no local ou proprietários da área, escolha dos melhores indicadores e análises dos resultados por meios gráficos, permitindo uma reflexão coletiva a respeito dos indicadores. Por ser uma metodologia de auto avaliação e participativa, mostra-se como uma ferramenta que permite a resolução dos problemas em uma área rural pela própria população residente nessa área (CASADO; MIELGO, 2007). 
Assim, esse trabalho teve por objetivos a criação, seleção e aplicação de indicadores de sustentabilidade, por meio de diagnóstico visual, composto por 26 parâmetros indicadores através da metodologia MESMIS, em duas áreas distintas, constituídas por um fragmento de mata nativa e por área de pastagem, próxima a uma nascente, ambas na Fazenda Pedra Branca, município de Caldas, no sul de Minas Gerais, que está inserida dentro da Área de Proteção Ambiental (APA) Santuário Ecológico da Pedra Branca.

\section{MATERIAL E MÉTODOS}

\section{1 Área de estudo}

A Fazenda Pedra Branca está localizada logo abaixo da Serra da Pedra Branca, no sul do estado de Minas Gerais, no município de Caldas. A Fazenda localiza-se dentro da APA Santuário Ecológico da Pedra Branca, com localização geográfica dada pelas coordenadas $21^{\circ} 58^{\prime} 06,6^{\prime \prime} \mathrm{S}$ e $46^{\circ} 23^{\prime} 15,5^{\prime} \mathrm{W}$, numa altitude média de 1200 m. Possui área de 60 ha, configurando 2,3 Módulos Fiscais (INCRA, 1980), o que a caracteriza como pequena propriedade familiar. Cerca de 24 ha ( $40 \%$ da propriedade) é composta por vegetação nativa, que faz parte do Domínio Atlântico (REZENDE et al., 2013). O restante da propriedade apresenta ocupação de pastagens para a criação de gado de leite e corte e vitivinicultura, com produção artesanal de vinho.

\subsection{Procedimentos}

Dentro da propriedade, foram selecionadas duas áreas distintas para a aplicação da metodologia: a primeira área é um fragmento da mata nativa, delimitada em aproximadamente 0,4 ha, inseridos nos 24 ha de mata nativa da propriedade. Já a segunda área foi delimitada em 0,2 ha e é composta por pastagem, localizada próxima a uma nascente (Figura 1). A escolha das áreas foi feita por apresentarem situações de uso e ocupação do solo distintas, que representam a propriedade como um todo.

Foram feitas três visitas na área, sendo realizadas duas visitas no período da manhã e duas visitas no período da tarde, visando realizar a percepção ambiental, para o melhor entendimento das condições locais. Cada visita teve uma duração 
média de quatro horas. Em conjunto com o proprietário da área, foram determinadas as principais características que podem indicar a sustentabilidade das áreas. Também foram verificados as características do agroecossistema em estudo, definindo os descritores, que indicam os aspectos a serem melhorados. Com base nessas informações, foram criados e selecionados indicadores que se relacionam às dimensões ambientais e socioeconômicas da área, resultando em 19 indicadores ambientais e sete indicadores socioeconômicos, agrupados na Tabela 1.

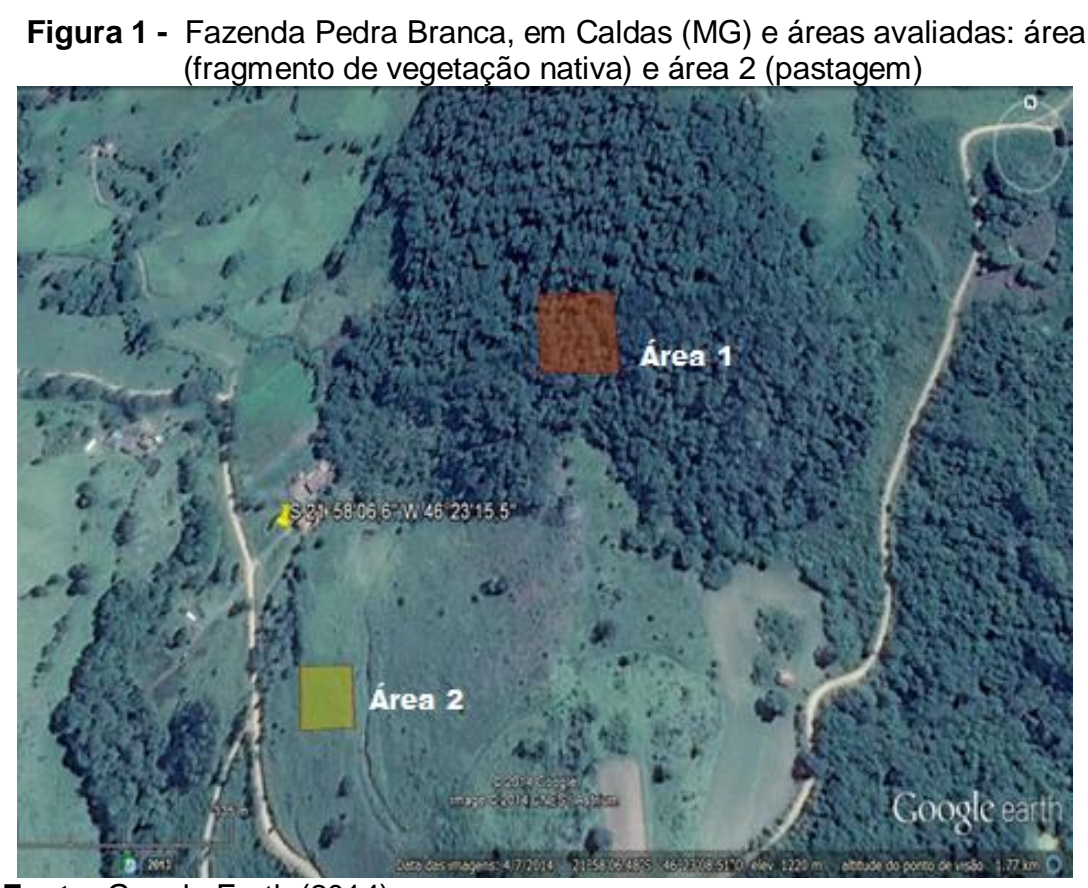

Fonte: Google Earth (2014)

Tabela 1 - Indicadores ambientais (números 1 ao 19) e socioeconômicos (números 20 ao 26) selecionados e com respectivas notas (1, 2 e 3) para aplicação em campo (continua)

\begin{tabular}{|c|c|c|c|c|}
\hline & & \multicolumn{3}{|c|}{ Nota } \\
\hline & & 1 & 2 & 3 \\
\hline \multicolumn{2}{|c|}{ Indicadores Ambientais } & \multicolumn{3}{|c|}{ Parâmetro* } \\
\hline 1 & $\begin{array}{l}\text { Presença de espécies } \\
\text { exóticas }\end{array}$ & Alta(> 50\%) & Média (entre $25 \%$ - $50 \%$ ) & Baixa $(<25 \%)$ \\
\hline 2 & $\begin{array}{l}\text { Isolamento de outros } \\
\text { fragmentos }\end{array}$ & Muito isolados & Medianamente isolados & $\begin{array}{l}\text { Pouco } \\
\text { isolados }\end{array}$ \\
\hline 3 & Microclima & Não perceptível & $\begin{array}{l}\text { Perceptível em alguns } \\
\text { pontos }\end{array}$ & $\begin{array}{l}\text { Perceptível em } \\
\text { área total }\end{array}$ \\
\hline 4 & $\begin{array}{l}\text { Presença de animais } \\
\text { silvestres }\end{array}$ & Não há & $\begin{array}{l}\text { Animais não ameaçados } \\
\text { de extinção }\end{array}$ & $\begin{array}{c}\text { Animais } \\
\text { ameaçados de } \\
\text { extinção }\end{array}$ \\
\hline 5 & Presença de clareira & Acima $30 \%$ & $10 \%-30 \%$ & $0-10 \%$ \\
\hline 6 & $\begin{array}{l}\text { Presença de processos } \\
\text { erosivos }\end{array}$ & $\begin{array}{c}\text { Elevado, presença } \\
\text { de sulcos e } \\
\text { voçorocas }\end{array}$ & $\begin{array}{c}\text { Médio, pouca presença } \\
\text { de sulcos }\end{array}$ & Ausente \\
\hline 7 & $\begin{array}{l}\text { Formação de crosta } \\
\text { superficial no solo }\end{array}$ & $\begin{array}{l}\text { Sim, em mais de } \\
50 \% \text { da área }\end{array}$ & $\begin{array}{c}\text { Sim, em menos de } 50 \% \\
\text { da área }\end{array}$ & Ausência \\
\hline
\end{tabular}


Tabela 1 - Indicadores ambientais (números 1 ao 19) e socioeconômicos (números 20 ao 26) selecionados e com respectivas notas (1, 2 e 3) para aplicação em campo

(conclusão)

\begin{tabular}{|c|c|c|c|c|}
\hline & \multicolumn{3}{|c|}{ Nota } \\
\hline & & 1 & 2 & 3 \\
\hline \multicolumn{2}{|r|}{ Indicadores Ambientais } & \multicolumn{3}{|c|}{ Parâmetro* } \\
\hline 8 & $\begin{array}{l}\text { Cor do solo e teor } \\
\text { matéria orgânica do solo }\end{array}$ & $\begin{array}{l}\text { Coloração mais } \\
\text { clara, teor muito } \\
\text { baixo de matéria } \\
\text { orgânica }\end{array}$ & $\begin{array}{c}\text { Coloração mais } \\
\text { escura, média matéria } \\
\text { orgânica }\end{array}$ & $\begin{array}{l}\text { Coloração bem } \\
\text { escura, muita } \\
\text { matéria orgânica }\end{array}$ \\
\hline 9 & $\begin{array}{l}\text { Profundidade da } \\
\text { camada escura } \\
\text { (horizonte O) do solo }\end{array}$ & $0-5 \mathrm{~cm}$ & $5-15 \mathrm{~cm}$ & $>15 \mathrm{~cm}$ \\
\hline 10 & Cobertura do solo & $\begin{array}{l}\text { Solo visualmente } \\
\text { pouco coberto, } \\
\text { pouca ou nenhuma } \\
\text { palhada, sem sinais } \\
\text { de decomposição }\end{array}$ & $\begin{array}{l}\text { Fina camada de palha, } \\
\text { cobertura do solo } \\
\text { acima de } 50 \%\end{array}$ & $\begin{array}{l}\text { Solo visualmente } \\
\text { bem coberto, } \\
\text { restos vegetais } \\
\text { em diferentes } \\
\text { estágios de } \\
\text { decomposição }\end{array}$ \\
\hline 11 & $\begin{array}{l}\text { Atividade biológica no } \\
\text { solo }\end{array}$ & $\begin{array}{l}\text { Sem sinais da } \\
\text { presença de } \\
\text { minhocas e/ou } \\
\text { artrópodes }\end{array}$ & $\begin{array}{c}\text { Presença de algumas } \\
\text { minhocas e/ou } \\
\text { artrópodes }\end{array}$ & $\begin{array}{l}\text { Abundância de } \\
\text { minhocas e } \\
\text { artrópodes }\end{array}$ \\
\hline 12 & $\begin{array}{l}\text { Atividade microbiológica } \\
\text { no solo }\end{array}$ & $\begin{array}{l}\text { Nenhuma ou baixa } \\
\text { efervescência do } \\
\text { solo com aplicação } \\
\text { de água oxigenada }\end{array}$ & $\begin{array}{l}\text { Média efervescência } \\
\text { do solo com aplicação } \\
\text { de água oxigenada }\end{array}$ & $\begin{array}{c}\text { Elevada } \\
\text { efervescência do } \\
\text { solo com } \\
\text { aplicação de água } \\
\text { oxigenada }\end{array}$ \\
\hline 13 & $\begin{array}{l}\text { Frequência média das } \\
\text { espécies arbustivo- } \\
\text { arbóreas }\end{array}$ & $\begin{array}{c}\text { Baixa (inferior a } \\
10 \% \text { ) }\end{array}$ & $\begin{array}{c}\text { Média (entre } 10 \% \text { e } \\
20 \% \text { ) }\end{array}$ & $\begin{array}{l}\text { Alta (acima de } \\
\qquad 20 \%)\end{array}$ \\
\hline 14 & $\begin{array}{l}\text { Diversidade de espécies } \\
\text { arbustivo-arbóreas }\end{array}$ & Baixa $(\alpha<2)$ & Média ( $\alpha$ entre 2 e 5 ) & Alta $(\alpha>5)$ \\
\hline 15 & Regeneração natural & Baixa & Média & Alta \\
\hline 16 & Herbivoria & Acima $50 \%$ & Entre $25 \%$ e $50 \%$ & Abaixo de $25 \%$ \\
\hline 17 & Numero estratos & 1 & 2 & 3 \\
\hline 18 & $\begin{array}{l}\text { Acesso de animais à } \\
\text { APP }\end{array}$ & Acesso livre & Pontos de abertura & Não há \\
\hline 19 & APP protegida & Inferior a $50 \%$ & Maior ou igual a $50 \%$ & $100 \%$ \\
\hline \multicolumn{2}{|c|}{$\begin{array}{l}\text { Indicadores } \\
\text { Socioeconômicos }\end{array}$} & \multicolumn{3}{|c|}{ Parâmetro } \\
\hline 20 & Presença lixo/entulho & $\begin{array}{l}\text { Presente em mais } \\
\text { de } 3 \text { locais }\end{array}$ & $\begin{array}{c}\text { Presente em menos } \\
\text { de } 3 \text { locais }\end{array}$ & Não há \\
\hline 21 & Queimadas & $\begin{array}{l}\text { Frequente (mais de } \\
\text { uma vez } a^{-1} \text { ) }\end{array}$ & $\begin{array}{l}\text { Esporádico (menos de } \\
\text { uma vez ao } \mathrm{ano}^{-1} \text { ) }\end{array}$ & Não há \\
\hline 22 & $\begin{array}{l}\text { Presença de esgoto no } \\
\text { entorno }\end{array}$ & Sem tratamento & Fossa & Tratamento \\
\hline 23 & $\begin{array}{l}\text { Aplicação agrotóxicos } \\
\text { nas proximidades }\end{array}$ & $\begin{array}{l}\text { Alta (mais de } 5 \\
\text { aplicações ano-1) }\end{array}$ & $\begin{array}{l}\text { Baixa (menos de } 5 \\
\text { aplicações ano }{ }^{-1} \text { ) }\end{array}$ & Não há \\
\hline 24 & Ocupação humana & $\begin{array}{l}\text { Alta (em mais de } \\
50 \% \text { da área) }\end{array}$ & $\begin{array}{c}\text { Média (entre } 25 \text { e } 50 \% \\
\text { da área) }\end{array}$ & $\begin{array}{l}\text { Baixa (em menos } \\
\text { de } 25 \% \text { da área) }\end{array}$ \\
\hline 25 & $\begin{array}{l}\text { Exploração econômica } \\
\text { da área }\end{array}$ & $\begin{array}{l}\text { Elevada (em mais } \\
\text { de } 50 \% \text { da área) }\end{array}$ & $\begin{array}{c}\text { Média (entre } 25 \text { e } 50 \% \\
\text { da área) }\end{array}$ & $\begin{array}{l}\text { Baixa (em menos } \\
\text { de } 25 \% \text { da área) }\end{array}$ \\
\hline 26 & $\begin{array}{l}\text { Utilização para fins } \\
\text { educacionais }\end{array}$ & Não há & Pouco frequente & Frequente \\
\hline
\end{tabular}

*Parâmetro: 1 - Otimo; 2 - Regular; 3 - Crítico.

Todas as avaliações foram visuais (avistamento) com exceção da avaliação de frequência média das espécies (razão entre o número de indivíduos da espécie e o 
número de indivíduos totais), calculando-se a média das frequências individuais de cada espécie e diversidade de espécies, com utilização do índice proposto por Margalef (1951), no qual o índice de diversidade é obtido pela equação:

$$
\text { Alfa }=(S-1) / \log N
$$

Onde:

Alfa = índice de diversidade; $\mathrm{S}=$ número de espécies; $\mathrm{N}=$ número de indivíduos. Assim, valores inferiores a 2,0 são considerados como característicos de áreas de baixa diversidade, enquanto valores superiores a 5,0 indicam áreas com diversidade elevada.

A avaliação do teor de matéria orgânica baseou-se apenas no aspecto visual, relacionado à coloração do solo, considerando, a partir da carta de Munsell, como coloração clara e teor muito baixo de matéria orgânica o valor 8 ou 7 e Croma 1 ou 2; coloração mais escura, com teor médio de matéria orgânica para o valor 6 ou 5 e Croma 3 ou 4; coloração bem escura, com muita matéria orgânica para o valor 4, 3 ou 2 e Croma 6 ou 8.

A metodologia foi aplicada numa visita a propriedade, com uma equipe multidisciplinar composta por dois Técnicos em Meio Ambiente, um Engenheiro Agrônomo e pelo proprietário da fazenda. Foram realizadas aplicações dos indicadores para as duas áreas separadas. Para cada parâmetro associado a um indicador, foram estabelecidas notas a serem atribuídas durante a aplicação da metodologia. Assim, o valor (3) corresponde a Ótimo, o valor (2) corresponde a Regular e o valor (1) a Crítico. Desse modo, em cada área, o valor máximo que poderia ser obtido era de 78 pontos. Foram feitas três para cada área e a avaliação da sustentabilidade baseou-se na soma das notas médias obtidas nas dimensões avaliadas.

Foi estabelecido o critério para avaliação final para cada área avaliada, baseado no somatório da média das notas atribuídas, indicando o grau de sustentabilidade de cada área. Assim, a pontuação inferior a 27 pontos indicou um sistema apresentando um elevado impacto, necessitando de um manejo rápido e intenso. A pontuação entre 27 e 51 pontos indicou um sistema pouco alterado, com pontos críticos a serem solucionados de forma efetiva. Já a pontuação superior a 51 
pontos indicou um sistema com elevado índice de sustentabilidade, necessitando de baixo manejo.

\section{RESULTADOS E DISCUSSÃO}

Após a aplicação dos indicadores, a nota obtida no fragmento de mata nativa foi de 45 pontos, enquanto que na área de pastagem foi de 45 pontos. As Figuras 2 e 3 apresentam a pontuação dos 38 indicadores, constantes na Tabela 1, nas duas áreas avaliadas. $\mathrm{O}$ valor 3 corresponde ao grau desejado de sustentabilidade, enquanto 0 valor 2 corresponde a um grau aceitável de sustentabilidade. O valor 1 corresponde, por sua vez, a um grau crítico de sustentabilidade.

Figura 2 - Notas para o fragmento de mata (Área 1) após a aplicação dos indicadores. Fazenda Pedra Branca, Caldas/MG, 2014

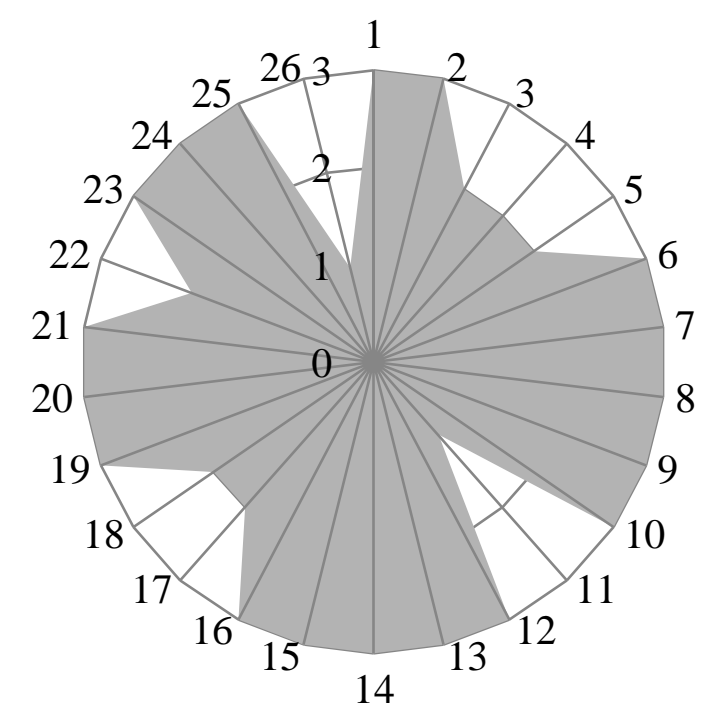


Figura 3 - Notas para a área de pastagem (Área 2) após a aplicação dos indicadores

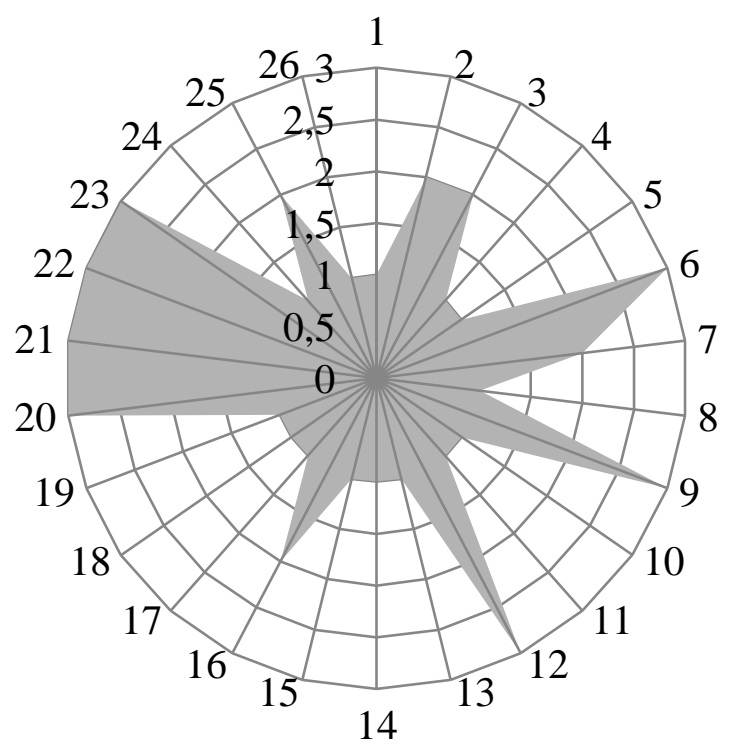

Assim, a área 1 (fragmento de mata) obteve uma nota final de 68 pontos, sendo considerada uma área com elevado índice de sustentabilidade, com necessidade de baixo manejo. a área 2 (pastagem), obteve nota final 45, indicando uma área pouco alterada, com pontos críticos necessitando de modos efetivos para serem solucionados.

Nessa área, foram identificados os seguintes pontos críticos: elevada presença de espécies exóticas e de clareiras, cor e teor de matéria orgânica do solo, reduzida cobertura do solo, atividade biológica do solo, frequência e diversidade de espécies arbustivo-arbóreas, regeneração natural e número de estratos, pouca proteção da Área de Preservação Permanente (APP), com acesso livre de animais e pouca utilização para fins educacionais.

A grande maioria desses pontos críticos relacionam-se ao fato da área 2 ser uma área de pastagem, basicamente composta por uma espécie, Brachiaria decumbens. Tsumanuma (2009) indica que $80 \%$ das áreas de pastagens no Brasil são cobertas por essa espécie. Plantas exóticas invasoras apresentam elevado potencial de modificar ambientes naturais, através de alterações físicas e biológicas do ambiente invadido e competição com espécies nativas por recursos ambientais. São consideradas a segunda maior ameaça à biodiversidade, atrás apenas da destruição de habitats por ações antrópicas diretas e acarretam também prejuízos à economia e riscos à saúde humana (ZILLER, 2001; CHRISTIANINI, 2006). Além disso, por ser um sistema de monocultura, promove uma alteração expressiva no ambiente, com redução na biodiversidade e desiquilíbrio ambiental, com 
consequências no empobrecimento e exaustão do solo, impactando em aspectos sociais e econômicos (ZIMMERMANN, 2009). Ao longo dos anos, áreas de pastagens vêm sendo exploradas em um sistema extrativista, com a implantação das espécies forrageiras através do uso da fertilidade natural dos solos que, sem cuidados, decresce com o tempo, reduzindo, nessas áreas, a capacidade suporte de animais (PEREIRA et al., 2013).

Desse modo, é indicado para a propriedade um manejo de integração entre a pecuária e a produção florestal, através da introdução de componentes arbóreos ou lenhosos nativos e diversificados, potencializando a terra, arquitetando sistemas ecológicos mais estáveis e minimizando o input de recursos externos, procurando obter uma maior autossuficiência. Sistemas de integração, nos quais espécies vegetais são cultivados na mesma área, mostram-se complexos e dinâmicos, principalmente pelas interações entre essas distintas culturas, animais e práticas realizadas nos locais nos quais são implantados. Assim, por basearem-se na integração espacial e temporal dos elementos do sistema produtivo, reduzindo a pressão sobre ecossistemas naturais, visando à obtenção de estratos elevados de qualidade ambiental, sem deixarem de mostrarem-se competitivos, esses sistemas tendem a elevar a sustentabilidade do uso dos solos (CORDEIRO et al., 2015)

É imprescindível que ocorra o restabelecimento da capacidade produtiva das plantas forrageiras em áreas degradas, com sistemas integrando pastagens com espécies florestais mostrando-se viáveis para a recuperação e renovação de áreas degradadas (OLIVEIRA et al., 2015). Nesse sentido, Carvalho e Xavier (2005) indicam que a distribuição de árvores na paisagem promove a contenção de processos erosivos, melhoria na conservação dos recursos hídricos, captura e fixação de $\mathrm{C}$ e $\mathrm{N}$, contribuindo para o aumento qualitativo da pastagem e propiciando conforto térmico aos animais, com reflexos na melhoria na qualidade da carne e leite. Também reduz custos de produção e promove a estabilização da renda nas propriedades rurais (ALVARENGA et al., 2010).

A inserção dos componentes arbóreos e lenhosos pode ser feita através da alocação de "ilhas" em pontos da pastagem ou através da utilização de aléias, que consiste no plantio de árvores ou arbustos em fileiras, com espaços entre as fileiras ocupados pela pastagem, com cortes periódicos da parte aérea dos componentes arbóreos, utilizados para a alimentação animal e também buscando uma maior elevação na biomassa do solo (MARIN; MENEZES; SALCEDO, 2007). A utilização de 
espécies madeireiras e/ou fixadoras de nitrogênio promovem, através da harmonização entre uso eficiente da terra e proteção ambiental, o aumento da renda do produtor e a elevação da sustentabilidade ambiental (NICODEMO et al., 2009).

Em relação aos indicadores acesso livre à APP e APP desprotegida, é indicada à adequação ambiental da nascente existente no local. Castro, Lima e Lopes (2007) indicam que processos de revitalização de nascentes são baseados em três princípios fundamentais: a proteção da superfície do solo, a redução de processos de evapotranspiração é a melhoria na infiltração de água no solo. No que diz respeito à recomposição da mata ciliar (APP) em nascentes, o código florestal atual, lei $n^{\circ}$ 12.651/2012 (BRASIL, 2012) determina que, em áreas rurais consolidadas, a recomposição de nascentes deve ocorrer num raio de 15 metros da nascente. Assim, como a área em estudo se enquadra nessas condições, com ocupação antrópica preexistente a 22 de julho de 2008, essa é a faixa de APP a ser recomposta, totalizando uma área de recomposição de $706,5 \mathrm{~m}^{2}$, que poderá ser feita através do plantio de mudas de espécies nativas da região, associada a uma regeneração natural da área. É importante o cercamento da nascente, para evitar que o gado entre nessa área, o que pode comprometer a regeneração do local.

\section{CONCLUSÕES}

1. A área composta pelo fragmento florestal apresentou índices de sustentabilidade superiores aos da área ocupada por pastagens, indicando que, no fragmento florestal é necessário um reduzido manejo da área. Já na área de pastagens, foram verificados vários pontos críticos, que devem ser solucionados de forma efetiva, para melhoria das condições do agroecossistema.

2. Os principais pontos críticos encontrados na área de pastagem relacionam-se a pouca diversidade ecológica da área, que é ocupada por Brachiaria decumbens. Assim, são propostas alternativas para aumentar a diversificação na área, como uma integração entre o manejo da pastagem e a produção florestal, através de introdução de componentes arbóreo-arbustivos no sistema, localizados em ilhas ou aléias. 
3. O manejo sugerido aos indicadores Acesso de animais na APP ( $\left.n^{\circ} 18\right)$ e APP protegida $\left(n^{\circ} 19\right)$ é o cercamento e adequação ambiental da área à legislação, que também refletirá na melhoria dos pontos críticos observados.

\section{REFERÊNCIAS}

ALVARENGA, R. C.; SILVA, V. P. da; GONTIJO NETO, M. M; VIANA, M. C. M.; VILELA, L. Sistema Integração Lavoura-Pecuária-Floresta: condicionamento do solo e intensificação da produção de lavouras. Informe Agropecuário, v. 31, p. 59-67, 2010.

ASTIER, M.; GARCÍA-BARRIOS, L.; GALVÁN-MIYOSHI, Y.; GONZÁLES-ESQUIVEL, C. E.; MASERA, O. R. Assessing the sustainability of small farmer natural resource management systems. A critical analysis of the MESMIS program (1995-2010). Ecology and Society, v. 17, n. 3, art. 25, 2012.

BRASIL. Lei no 12.651, de 25 de maio de 2012. Dispõe sobre a proteção da vegetação nativa; altera as Leis $\mathrm{n}^{\mathrm{os}}$ 6.938, de 31 de agosto de 1981, 9.393, de 19 de dezembro de 1996, e 11.428, de 22 de dezembro de 2006; revoga as Leis $\mathrm{n}^{\circ 5} 4.771$, de 15 de setembro de 1965, e 7.754, de 14 de abril de 1989, e a Medida Provisória no 2.166-7, de 24 de agosto de 2001 e dá outras previdências. Brasília: Presidência da República, 2012.

CÂNDIDO, G. A.; NÓBREGA, M. M.; FIGUEIREDO, M. T. M.; SOUTO MAIOR, M. M. Avaliação da sustentabilidade de unidades de produção agroecológicas: um estudo comparativo dos métodos IDEAS e MESMIS. Ambiente \& Sociedade, v. 18, n. 3, p. 99-120, 2015.

CARVALHO, H. M. Padrões de sustentabilidade: uma medida para o desenvolvimento sustentável. Curitiba, 1993. 26 p.

CARVALHO, M. M.; XAVIER, D. F. Sistemas silvipastoris para recuperação e desenvolvimento de pastagens. In: AQUINO, A. M. de; ASSIS, R. L. de (org.). Agroecologia: princípios e técnicas para uma produção orgânica sustentável. Brasília: Embrapa Informação Tecnológica, 2005, p. 498-517.

CASADO, G. I. G.; MIELGO, A, M. A. La investigación participativa em agroecología: uma herramienta para el dasarrollo sustentable. Ecossistemas, v. 16, n. 1, p. 24-36, 2007.

CASTRO, P. S; LIMA, F. Z.; LOPES, J. D. S. Recuperação e conservação de nascentes. Viçosa: CPT, 2007. 272 p.

CHRISTIANINI, A. V. Fecundidade, dispersão e predação de sementes de Archontophoenix cunninghamiana $\mathrm{H}$. Wendl. \& Drude, uma palmeira invasora da Mata Atlântica. Revista Brasileira de Botânica. São Paulo, v. 29, n. 4, 2006.

CORDEIRO, L. A. M.; VILELA, L.; MARCHÃO, R. L.; KLUTHCOUSKI, J.; MARTHA JÚNIOR, G. B. Integração lavoura-pecuária e lavoura-pecuária-floresta: estratégias para a intensificação sustentável do uso do solo. Cadernos de Ciência \& Tecnologia, v. 32, n. 1/2, p. 15-43, 2015.

DEPONTI, C. M.; ECKERT, C.; AZAMBUJA, J. L. B. Estratégia para construção de indicadores para avaliação da sustentabilidade e monitoramento de sistemas. Agroecologia e Desenvolvimento Rural Sustentável, v. 3, n. 4, p. 44-52, 2002. 
GLIESSMAN, S. R. Agroecologia: processos ecológicos em agricultura sustentável. Porto Alegre: Ed. Universidade/UFRGS, 2009. 658 p.

GUIMARÃES, N. F.; GALLO, A. S.; SANTOS, C. C.; MORINIGO, K. P. G.; BENTOS, A. B.; CARVALHO, E. M. Avaliação da sustentabilidade de um agroecossistema pelo método MESMIS. Scientia Plena, v. 11, n. 5, p. 1-11, 2015.

INSTITUTO NACIONAL DE COLONIZAÇÃO E REFORMA AGRÁRIA (INCRA). Instrução especial no 20, de 28 de maio de 1980. Estabelece o Módulo Fiscal de cada Município, previsto no Decreto no 84.685, de 06 de maio de 1980. Brasília: INCRA, 1980.

KEMERICH, P. D. C.; MARTINS, S. R.; KOBIYAMA, M.; BURIOL, G. A.; BORBA, W. F.; RITTER, L. G. Avaliação da sustentabilidade ambiental em bacias hidrográficas mediante a aplicação do modelo P-E-R. Revista Eletrônica em Gestão, Educação e Tecnologia Ambiental, v. 10, n. 10, p. 2140-2150, 2013.

KEMERICH, P. D. C.; RITTER, L. G.; BORBA, W. F. Indicadores de sustentabilidade ambiental: métodos e aplicações. Revista Monografias Ambientais, v. 13, n. 05, p. 37233746, 2014.

MALHEIROS, T. F.; PHILIPPI JR., A.; COUTINHO, S. M.V. Agenda 21 nacional e indicadores de desenvolvimento sustentável: contexto brasileiro. Revista Saúde e Sociedade, São Paulo, v. 17, n. 1, p. 7-20, 2008.

MARIN, A. M. P.; MENEZES, R. S. C.; SALCEDO, J. H. Produtividade de milho solteiro ou em aléias de gliricídia adubado com duas fontes orgânicas. Pesquisa Agropecuária Brasileira, v. 42 , n. 5, p. 669-677, 2007.

MARGALEF, R. Diversidad de espécies em lãs comunidades naturales. Publicaciones del Instituto de Biologia Aplicada. Barcelona, v. 6, p. 59-72, 1951.

MOURA, L. G. V.; ALMEIDA, J.; MIGUEL, L. A. Avaliação de sustentabilidade em agroecossistemas: um pouco de pragmatismo. Revista Redes, v. 9, n. 2, p. 133-155, 2004.

NICODEMO, M. L. F; SILVA, V. P.; SANTOS, P. M.; VINHOLI, M. M. B.; FREITAS, A. R.; CAPUTTI, G. Desenvolvimento inicial de espécies florestais em sistema silvipastoril na região sudeste. Pesquisa Florestal Brasileira, v. 29, n. 60, p. 89-92 (edição especial), 2009.

OLIVEIRA, F. L. R.; CABACINHA, C. D.; SANTOS, L. D. T.; BARROSO, D. G.; SANTOS JÚNIOR, A.; BRANT, M. C.; SAMPAIO, R. A. Crescimento inicial de eucalipto e acácia, em diferentes arranjos de integração lavoura-pecuária-floresta. Revista Cerne, v. 21, n. 2, p. 227233, 2015.

PEREIRA, D. N.; OLIVEIRA, T. C.; BRITO, T. E.; AGOSTINI, J. A. F.; LIMA, P. F.; SILVA, A. V.; SANTOS, C. S.; BREGAGNOLI, M. Diagnóstico e recuperação de áreas de pastagens degradadas. Revista Agrogeoambiental, n. 1, p. $49-53$ (edição especial), 2013.

REZENDE, M. G.; ELIAS, R. C. L.; SALIMENA, F. R. G.; MENINI NETO, L. Flora vascular da Serra da Pedra Branca, Caldas, Minas Gerais e relações florísticas com áreas de altitude da Região Sudeste do Brasil. Biota Neotropica, v. 13, n. 4, p. 201-224, oct/dez. 2013.

RUIZ, F. A.; MENA, Y.; SAYADI, S.; CASTEL, J. M.; NAVARRO, L.; NAHED, J. Social indicators for evaluating sustainability of goat livestock farms: methodological approach. Tropical and subtropical agroecosystems, v. 11, n. 01, p. 65-68, 2009. 
SANTANA, L. K. A.; MACIEL, P. B.; RODRIGUES, S. R. S.; LIRA, W. S. Indicadores sociais para avaliar a sustentabilidade na agricultura familiar da comunidade do Arrasto no município de Queimadas - PB. Qualitas Revista Eletrônica, v. 16, n. 1, p. 1-16, 2015.

SPEELMAN, E. N.; LÓPEZ-RIDAURA, S.; COLOMER, N. A.; ASTIER, M. Ten years of sustainability evaluation using the MESMIS framework: lessons learned from its application in 28 Latin American case studies. International Journal of Sustainable Development \& World Ecology, v. 14, iss. 04, p. 345-361, 2007.

TSUMANUMA G. M. Diversas espécies de braquiárias podem compor integração. Visão Agrícola, n. 09, p. 28-29, 2009.

VERONA, L. A. F. Avaliação de sustentabilidade em agroecossistema de base familiar e em transição agroecológica na região sul do Rio Grande do Sul. 2008. 193 f. Tese (Doutorado) - Universidade Federal de Pelotas, Pelotas, 2008.

VERONA, L. A. F; CASALINHO, H.; MASERA, O.; GALVÁN, Y.; CORRÊA, I.; SCHWENGBER, J. Uso de indicadores compostos na análise da sustentabilidade de agroecossistemas de base familiar na região sul do Rio Grande do Sul. Revista Brasileira de Agroecologia, v. 2, n. 2, p. 491-494, 2007.

ZILLER, S. R. Plantas exóticas invasoras: a ameaça da contaminação biológica. Ciência Hoje, v. 30, n. 178, p. 77-79, 2001.

ZIMMERMANN, C.L. Monocultura e transgenia: impactos ambientais e insegurança alimentar. Veredas do Direito, Belo Horizonte, v. 06, n. 12, p. 79-100, 2009. 